\title{
Prognostic outcome after second primary lung cancer in patients with previously treated lung cancer by radiotherapy
}

\author{
Yijun Wu ${ }^{1,2}$, Chang Han ${ }^{2}$, Jiawei Zhu ${ }^{1,2}$, Yuming Chong ${ }^{2}$, Jianghao Liu ${ }^{2}$, Liang Gong ${ }^{2}$, Zhikai Liu ${ }^{1 \#}, \mathrm{Ke} \mathrm{Hu}^{1 \#}$, \\ Fuquan Zhang ${ }^{1 \#}$ \\ ${ }^{1}$ Department of Radiation Oncology, Peking Union Medical College Hospital, Chinese Academy of Medical Sciences \& Peking Union Medical \\ College, Beijing, China; ${ }^{2}$ Peking Union Medical College, Eight-Year MD Program, Chinese Academy of Medical Sciences, Beijing, China \\ Contributions: (I) Conception and design: F Zhang, K Hu, Y Wu; (II) Administrative support: F Zhang; (III) Provision of study materials or patients: \\ Y Wu; (IV) Collection and assembly of data: Y Wu, C Han, J Zhu, J Liu, Y Chong, L Gong; (V) Data analysis and interpretation: Y Wu, C Han, Z \\ Liu; (VI) Manuscript writing: All authors; (VII) Final approval of manuscript: All authors. \\ "These authors contributed equally to this work. \\ Correspondence to: Fuquan Zhang, MD. Department of Radiation Oncology, Peking Union Medical College Hospital, Chinese Academy of Medical \\ Sciences \& Peking Union Medical College, Beijing, China. Email: zhangfq@pumch.cn.
}

Background: Second primary lung cancer (SPLC) occurs not rarely in recent years. The effect of radiotherapy on SPLC remains unclear. This study aims to explore the survival outcome of SPLC patients with clinical stage T1 lung cancer previously treated with radiotherapy.

Methods: A total of 705 SPLC patients that previously underwent radiotherapy for first primary lung cancer (FPLC) were identified from the Surveillance, Epidemiology, and End Results (SEER) database between 2004 and 2016. Univariate and multivariate Cox regression analyses were performed to find prognostic factors. The survival outcomes were plotted using Kaplan-Meier (KM) method and compared by log-rank test. Additionally, propensity score matching (PSM) analyses were used to compare overall survival (OS) and lung cancer-specific survival (CSS) between radiotherapy and other treatment groups for SPLC.

Results: According to Cox analyses, age $>62$ years [hazard ratio (HR): 1.48, $95 \%$ confidence interval (CI): 1.10-1.99; $\mathrm{P}=0.010]$, SPLC tumor size $>1 \mathrm{~cm}$ (HR: 1.95, 95\% CI: $1.51-2.53 ; \mathrm{P}<0.001$ ), and treatments for SPLC as chemotherapy (HR: 1.39, 95\% CI: 1.13-1.71; P=0.002), no surgery (HR: $2.00,95 \% \mathrm{CI}$ : 1.34-2.98; $\mathrm{P}=0.001$ ) and no radiotherapy (HR: 1.73, 95\% CI: 1.39-2.15; $\mathrm{P}<0.001)$ independently indicated worse survival. After PSM, patients treated with radiotherapy for SPLC had significantly better OS and CSS than the none-treatment (OS: $\mathrm{P}=0.004$; CSS: $\mathrm{P}<0.001)$, chemotherapy $(\mathrm{P}<0.001)$ or radiotherapy plus chemotherapy (OS: $\mathrm{P}=0.032$; CSS: $\mathrm{P}=0.008$ ) groups, but demonstrated a worse $\mathrm{OS}$ than the surgery group $(\mathrm{P}=0.034)$.

Conclusions: Surgery may be more beneficial to survival than radiotherapy and chemotherapy and should be considered first if possible. When patients cannot tolerate surgery, radiotherapy can be an effective alternative.

Keywords: Second primary lung cancer (SPLC); radiotherapy; survival analysis; propensity score matching analysis (PSM analysis)

Submitted May 24, 2020. Accepted for publication Sep 09, 2020.

doi: $10.21037 /$ jtd-20-2024

View this article at: http://dx.doi.org/10.21037/jtd-20-2024

(C) Journal of Thoracic Disease. All rights reserved. 


\section{Introduction}

Lung cancer remains the one with the highest cancerrelated mortality in the world (1). In recent years, the rapid advancement and wide application of low-dose computed tomography (CT) have made it possible to find more cases of lung cancer (2). Multiple primary lung cancer (MPLC), which was defined in 1975 by Martini and Melamed (3), also showed an increased incidence as the development of screening methods. Patients diagnosed with first primary lung cancer (FPLC) might be of a high risk for developing a second primary lung cancer (SPLC) (4). One previous study reported $2.95 \%$ of 156,494 lung cancer patients suffered a SPLC in the study population from the Surveillance, Epidemiology, and End Results (SEER) database between 1992 and 2007 (5). In spite of the fact that an inspiring survival outcome has been obtained for early-stage lung cancer (6), the clinical management and prognosis of SPLC patients still remain unclear. Considering the worse survival of SPLC patients, it is particularly necessary to conduct prognostic studies for selecting potential survival indicators and identifying optimal treatment strategies.

Currently, surgical resection predominates in the curable medical interventions for early-stage lung cancer. Radiotherapy, which has gone through high-quality improvements in the past decades, can be an effective alternative to surgery. Stereotactic ablative radiotherapy (SABR) has been considered the standard treatment for inoperable early-stage lung cancer patients, especially the elderly (7). Several studies also showed a similar survival outcome between surgical resection and $\operatorname{SABR}(8,9)$. However, little is known about the effect of radiotherapy on the survival of SPLC patients.

The SEER database collected the cancer data of incidence and survival that covered approximately $30 \%$ of the American cancer patients. Specifically, the dataset of multiple primary cancer in this database is available, which defines MPLC based on the followings: (I) topography; (II) histology; (III) solitary tumors that located at each lung; (IV) time interval between the diagnosis of two tumors more than 3 years; or (V) more than 60 days between the first in situ carcinoma and the second invasive carcinoma $(10,11)$. Actually, in spite of the commonly-accepted Martini criteria (3), it is still difficult to distinguish MPLC from pulmonary metastasis. Thus, in the present study, we identified SPLC patients that previously received radiotherapy for FPLC from the SEER database and compared the survival outcome between radiotherapy and other treatments for SPLC. The prognostic factors were also determined by analyzing the clinical and therapeutic characteristics associated with SPLC patients. We present the following article in accordance with the STROBE reporting checklist (available at http://dx.doi.org/10.21037/jtd-20-2024).

\section{Methods}

\section{Study population}

The study was conducted in accordance with the Declaration of Helsinki (as revised in 2013). Patients diagnosed with SPLC between 2004 and 2016 were identified from SEER database. The initial search strategy was set as: (I) number of tumors: two (person selection session); (II) tumor site: "lung and bronchus" (site recode ICD-O-3/WHO 2008); (III) sequence number for tumors (multiple primary fields): 1 st and 2 nd of two or more primaries; and (IV) diagnosis year of first primary tumor: 2004-2016. By further selection, we only enrolled clinical T1 stage FPLC (tumor size $\leq 3 \mathrm{~cm}$ ) patients who received radiotherapy (radiation recode: beam radiation) without undergoing surgical resection for FPLC (Figure 1). Since the SEER database was used publicly, all data included are anonymous and the relevant requirement about informed consent was thus waived. This study has been approved to be exempted research for no human subject involved by the Ethics Committee of Peking Union Medical College Hospital.

\section{Patients' characteristics}

The demographic characteristics of patients from SEER database included age at diagnosis of FPLC, race (white, black and others), sex (male and female), tumor size [CS tumor size (2004-2015)], tumor laterality (right and left), tumor site (primary site-labeled: upper lobe, middle lobe, lower lobe and main bronchus), clinical TNM stage of FPLC [derived AJCC TNM, 7th ed (2010-2015)]. Patients were then restaged based on the 8 th edition TNM staging system (12). The TNM stage of SPLC was not included in this study because there is still lack of evidence-based staging tool for MPLC.

Treatment information included surgery [RX SummSurg Prim Site (1998+): code 33 (lobectomy), code 21 (wedge resection) and code 22 (segmentectomy)], chemotherapy and radiotherapy (radiation recode: beam radiation). Wedge resection and segmentectomy were 


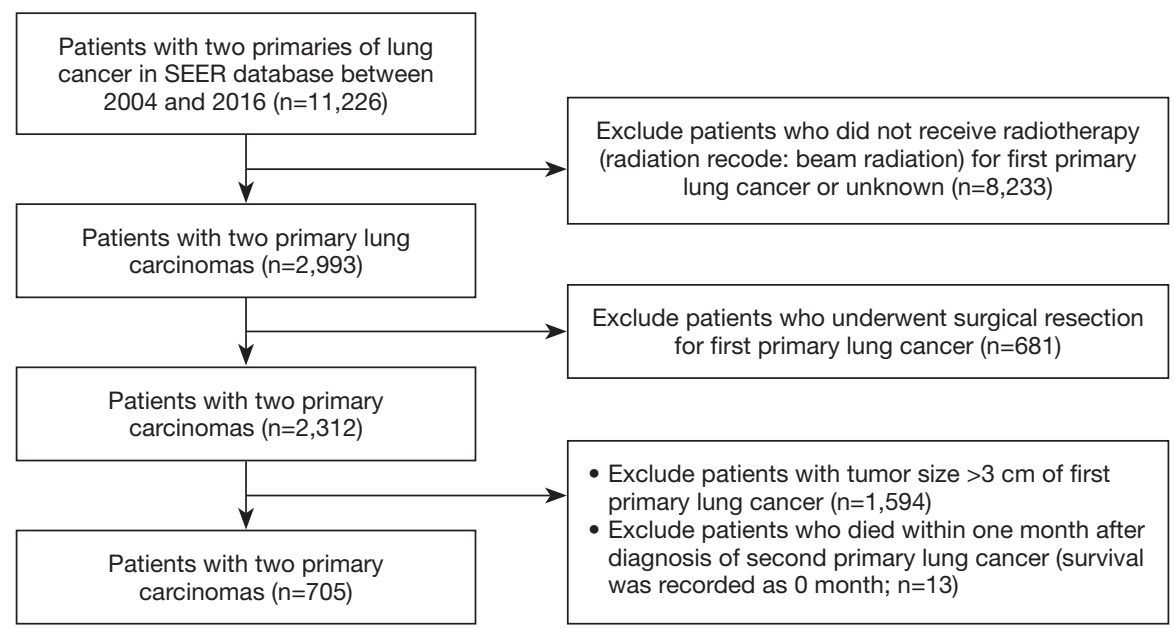

Figure 1 The selection flowchart of the study cohort from the SEER database. SEER, Surveillance, Epidemiology, and End Results.

integrated into sublobar resection group. The follow-up and survival data were also extracted from the database with the information update time that ended in December, 2016. Overall survival (OS) and disease (lung cancer)-specific survival (CSS) were used to compare the survival outcome. In the analyses of CSS, only deaths for lung cancer-related cause (COD to site recode: "lung and bronchus") were counted. This study focused on the survival time after the diagnosis of SPLC. The time interval (months) between the diagnoses of both primaries was also calculated.

\section{Statistical analysis}

From the SEER database, two kinds of variables (continuous and classified) that described patients' demographic characteristics were obtained using SEER*Stat software (version 8.3.5). $\mathrm{P}$ value $<0.05$ (two-side) was considered statistically significant. The continuous variables included age at diagnosis, tumor sizes of both primary tumors and diagnosis interval. All statistical analyses were performed using R software (version 3.6.3; http://www.r-project.org). With considering clinical usefulness, continuous variables were categorized into classified ones, using a k-adaptive partitioning algorithm ("kaps" R package), which provides an effective approach to identifying optimal cutoff points of continuous variables in the prognostic studies (13). To find potential prognostic factors for SPLC patients, Cox proportional hazard analyses were performed by forward stepwise regression. Variables with certain significance
$(\mathrm{P}$ value $<0.10)$ in the univariate analysis were selected for multivariate analysis. Survival curves of OS and CSS were constructed using Kaplan-Meier (KM) method and compared by log-rank test. Besides, to conduct more reliable survival comparisons, propensity score matching (PSM; "MatchIt" R package) was used to compare the survival outcome between radiotherapy and other treatments for SPLC. Demographic characteristics between after-matching groups were compared by Pearson's Chi square test (or Fisher's exact test when necessary).

\section{Results}

\section{Demographic characteristics}

There was a total of 705 SPLC patients enrolled in our study, including 301 males and 404 females (Table 1). The median age was 71 [interquartile range (IQR): 66-77] years. Among all patients, $84.4 \%$ [595] presented a FPLC diagnosis age older than 62 years. The white race people accounted for the majority of study population (86.0\%, 606/705). All enrolled patients were marked as "Active" follow-up. The median follow-up time since the diagnosis of SPLC was 17 (IQR: 9-30) months, while that of the interval between diagnoses of two primaries was 30 (IQR: $3-$ 52 ) months. Until the update time of follow-up, the OS rate was $37.0 \%(261 / 705)$. Of all deaths, $339(77.0 \%)$ patients died from the lung cancer-related and 105 (23.0\%) from other causes. All patients received radiotherapy for FPLC, while 215 (30.4\%) patients also received chemotherapy. 
Table 1 Univariate and multivariate Cox regression analysis of OS for SPLC patients

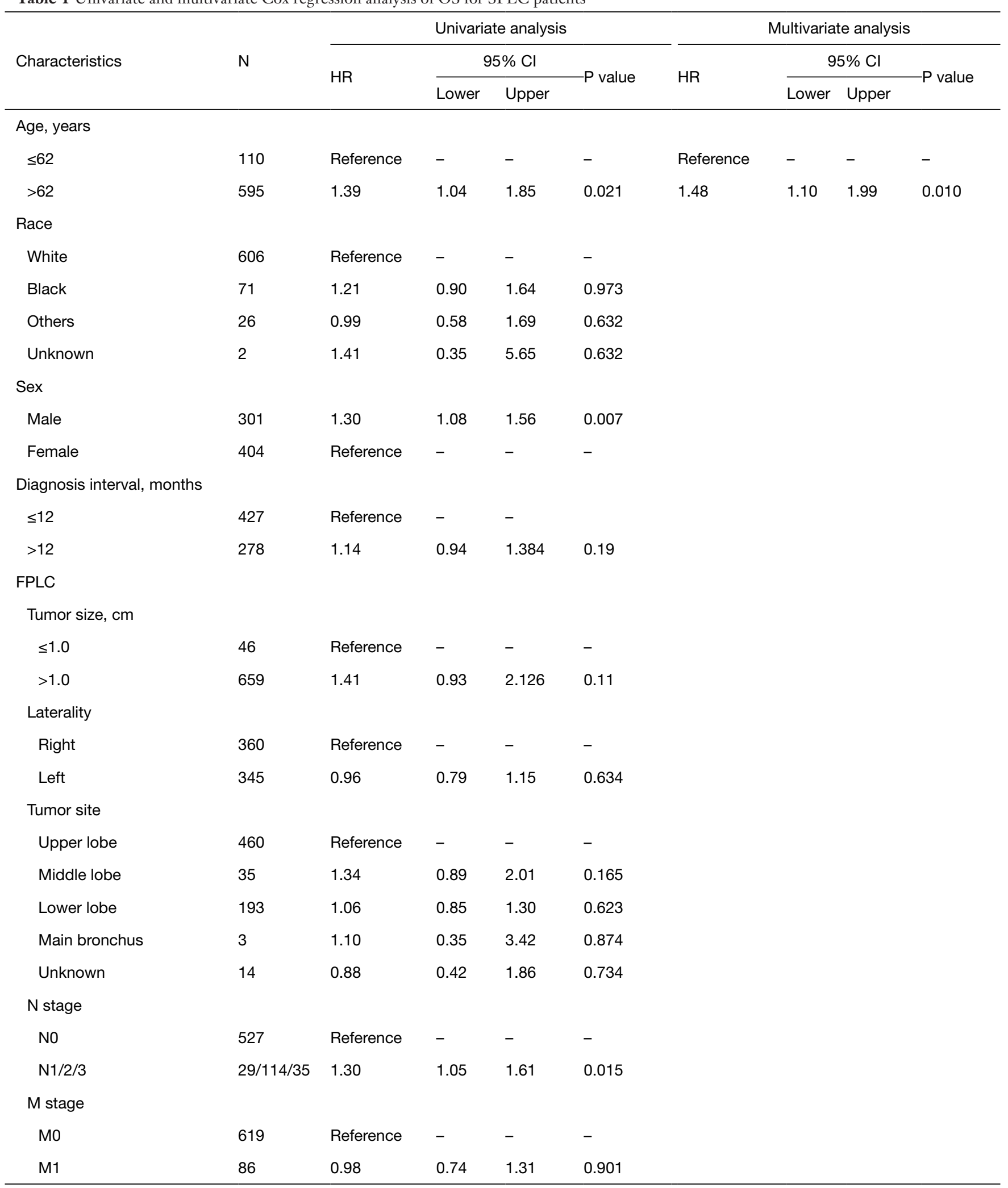

Table 1 (continued) 
Table 1 (continued)

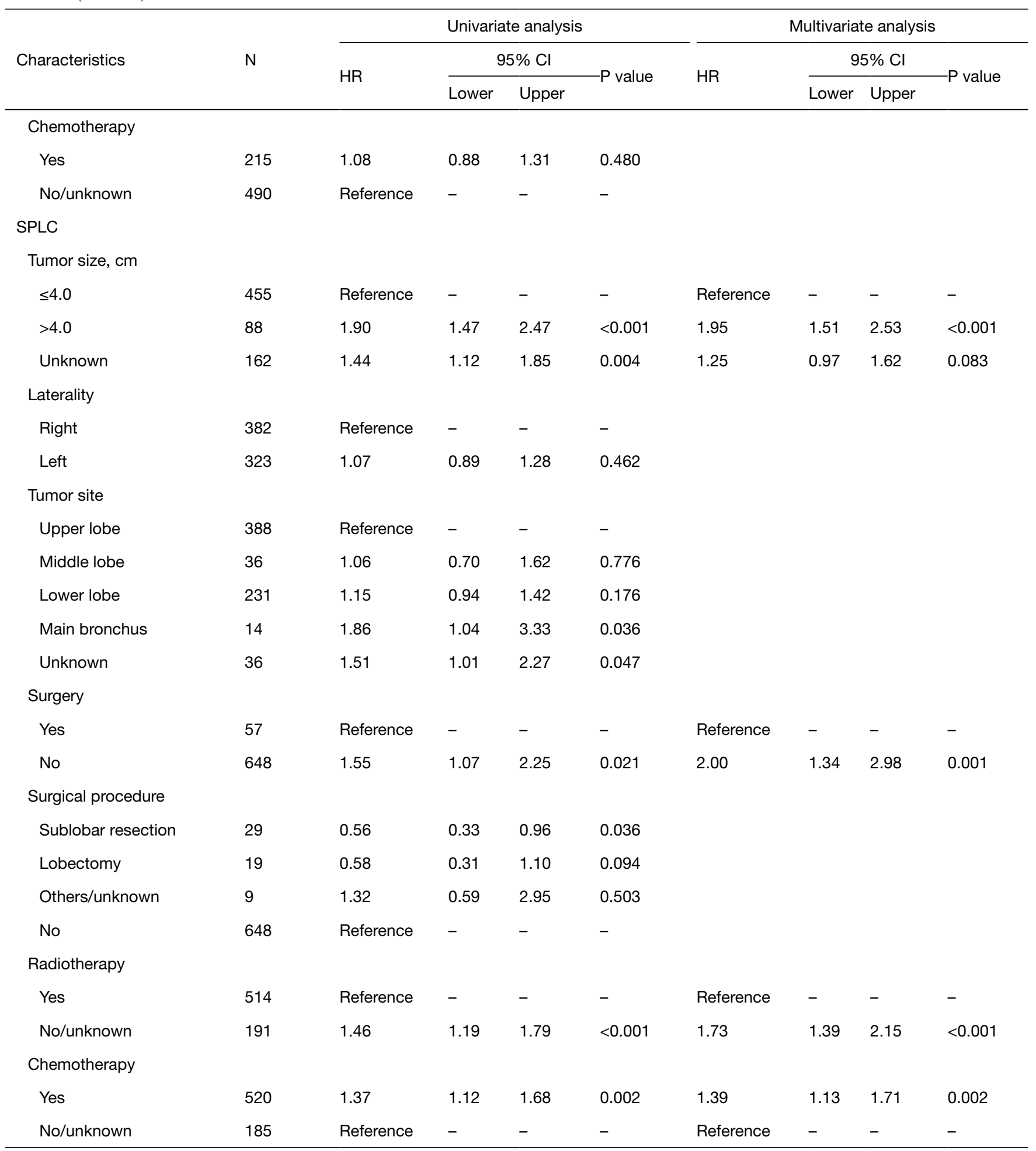

OS, overall survival; SPLC, second primary lung cancer; FPLC, first primary lung cancer; HR, hazard ratio; Cl, confidence interval. 
A

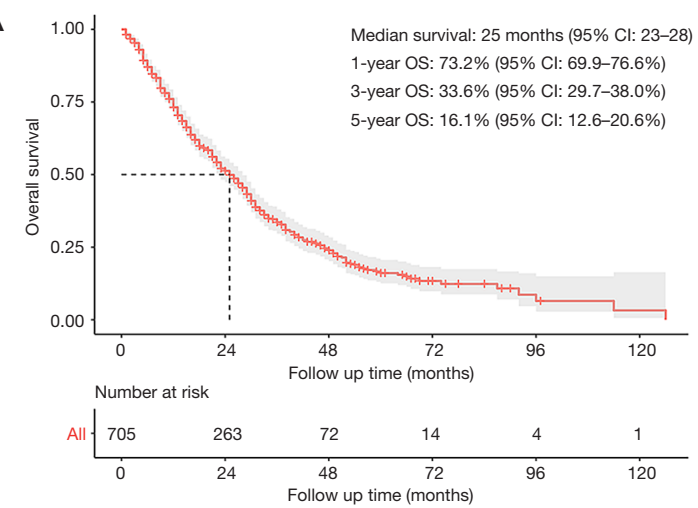

C

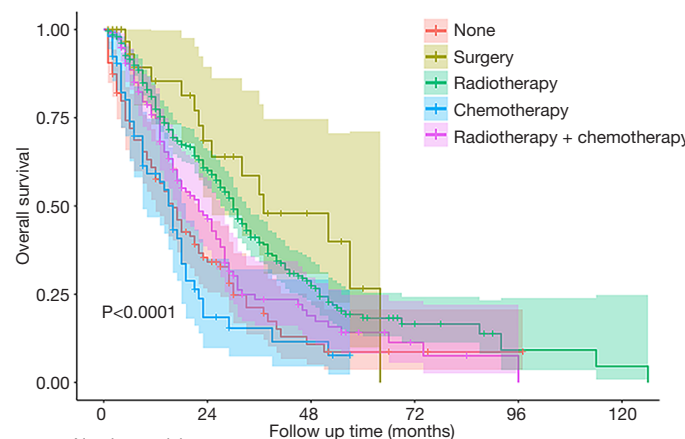

B

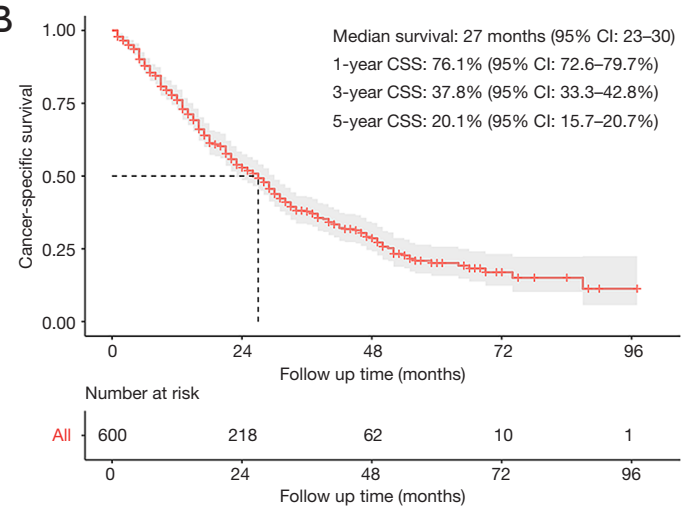

D

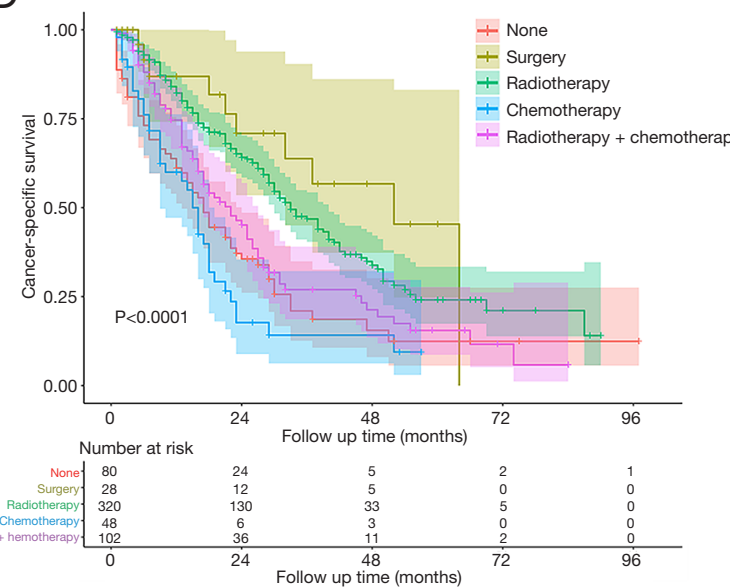

Figure 2 Survival analysis for SPLC before PSM. (A) OS and (B) lung CSS analysis for all patients; (C) OS and (D) CSS analysis between different treatment groups. SPLC, second primary lung cancer; PSM, propensity score matching; OS, overall survival; CSS, cancer-specific survival; CI, confidence interval.

\section{Univariate and multivariate Cox regression analysis}

According to the univariate analysis (Table 1), a worse survival following the diagnosis of SPLC was significantly associated with age $>62$ years [hazard ratio (HR): $1.39,95 \%$ confidence interval (CI): 1.04-1.85; $\mathrm{P}=0.021]$, male sex (HR: 1.30, 95\% CI: $1.08-1.56 ; \mathrm{P}=0.007)$, positive $\mathrm{N}$ stage of FPLC (HR: 1.30, 95\% CI: 1.05-1.61; P=0.015) and SPLCrelated characteristics as tumor size $>1 \mathrm{~cm}$ (HR: 1.90, 95\% CI: 1.47-2.47; $\mathrm{P}<0.001)$, main bronchus of tumor sites (vs. upper lobe: HR: 1.86, 95\% CI: 1.04-3.33; $\mathrm{P}=0.036$ ), no surgery (HR: $1.55,95 \% \mathrm{CI}: 1.07-2.25 ; \mathrm{P}=0.021$ ), no radiotherapy (HR: 1.46, 95\% CI: 1.19-1.79; $\mathrm{P}<0.001$ ) and chemotherapy (HR: 1.37, 95\% CI: 1.12-1.68; $\mathrm{P}=0.002$ ). Multivariate analysis showed that age $>62$ years (HR: 1.48 , 95\% CI: $1.10-1.99 ; \mathrm{P}=0.010)$, tumor size $>1 \mathrm{~cm}$ (HR: 1.95, 95\% CI: $1.51-2.53 ; \mathrm{P}<0.001)$ and three therapeutic strategies of SPLC significantly influenced the survival outcome. The absence of surgery (HR: 2.00, 95\% CI: 1.34 $2.98 ; \mathrm{P}=0.001$ ) or radiotherapy (HR: $1.73,95 \%$ CI: 1.39 $2.15 ; \mathrm{P}<0.001)$ indicated a worse survival, while patients with the absence of chemotherapy (chemotherapy $v s$. no chemotherapy, HR: 1.39, 95\% CI: 1.13-1.71; $\mathrm{P}=0.002$ ) showed a better survival.

\section{Survival analysis before PSM}

As shown in Figure 2, the median survival time for the entire study population was 25 (95\% CI: 23-28) months for OS and 27 (95\% CI: 23-30) months for CSS. The 1-, 3and 5 -year rates of OS were $73.2 \%$ (95\% CI: 69.9-76.6\%), $33.6 \%$ (95\% CI: $29.7-38.0 \%$ ) and $16.1 \%$ (95\% CI: 12.6-20.6\%), respectively, while those of CSS were $76.1 \%$ (95\% CI: $72.6-79.7 \%$ ), $37.8 \%$ (95\% CI: $33.3-42.8 \%$ ) and 


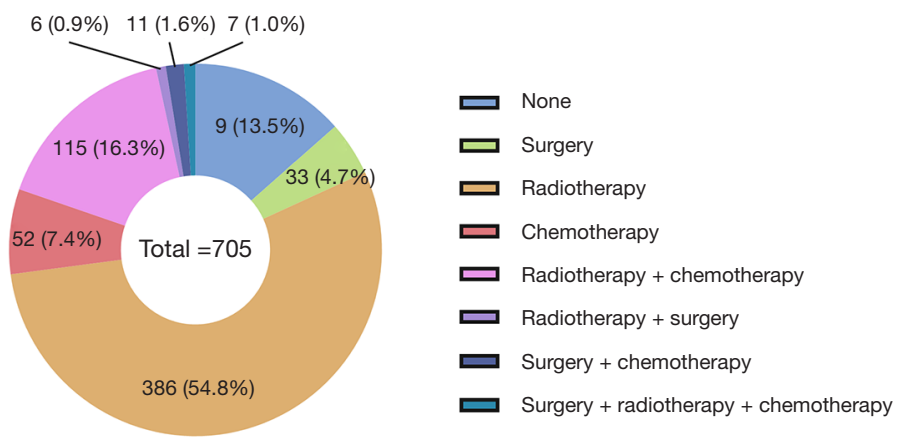

Figure 3 The number and percentage of patients at each treatment strategy.

20.1\% (95\% CI: 15.7-20.7\%), respectively (Figure 2A,B). The survival analysis of subgroups based on identified prognostic indicators was showed in Figures S1,S2. All the five indicators demonstrated significant difference $(\mathrm{P}<0.05)$ in both OS and CSS curves by log-rank test except age $>62$ years, which did not present significantly worse lung CSS than those with age $\leq 62$ years $(\mathrm{P}=0.055$; Figure $S 1 B)$.

The treatment strategies for SPLC mainly included surgery $(4.7 \%, 33 / 705)$, radiotherapy $(54.8 \%, 386 / 705)$, chemotherapy $(7.4 \%, 52 / 705)$ and radiotherapy plus chemotherapy (16.3\%, 115/705; Figure 3). There were $95(13.5 \%)$ patients that received none of treatments. The survival comparisons between the treatment groups were shown in Figure 2C,D. The radiotherapy group had significantly better survival than none-treatment $(\mathrm{P}<0.001)$, chemotherapy $(\mathrm{P}<0.001)$ and radiotherapy plus chemotherapy (OS: $\mathrm{P}=0.006$; CSS: $\mathrm{P}<0.001$ ) in both OS and CSS curves. However, it seemed that the surgery group performed better than radiotherapy but not significantly (OS: $\mathrm{P}=0.200$; CSS: $\mathrm{P}=0.240$ ).

\section{Survival analysis after PSM}

Considering the data bias of demographic factors, PSM between different treatment groups was used to minimize confounding effects. The baseline characteristics (age, race, sex, tumor size, laterality, tumor site and treatment strategies for SPLC) were incorporated into matching analysis. For each comparison, most of characteristics were well matched (Tables S1-S4). Similarly, patients who underwent radiotherapy for SPLC had significantly better OS and CSS than the study population of none-treatment (OS: $\mathrm{P}=0.004$; CSS: $\mathrm{P}<0.001$; Figure 4), chemotherapy $(\mathrm{P}<0.001$; Figure $5 A, B)$ or radiotherapy plus chemotherapy (OS: $\mathrm{P}=0.032$;
CSS: $\mathrm{P}=0.008$; Figure 5C,D). However, after matching, the surgery group demonstrated a significantly better OS than radiotherapy ( $\mathrm{P}=0.034$; Figure $4 C$ ), though the difference of CSS was not significant $(\mathrm{P}=0.540$; Figure $4 D)$.

\section{Discussion}

Currently, multiple lung carcinomas have not been the rare cases since the wide application of low-dose CT. MPLC, which has been reported more frequently in recent years, remains to be an emerging challenge with several issues that need to be urgently solved, including accurate diagnoses, appropriate treatments and reasonable follow-up periods. Actually, MPLC is difficult to be distinguished from pulmonary metastasis, and could not be well described and staged until the 8 th edition TNM staging system (12). Exactly as the criteria suggested by Martini (3) and American College of Chest Physicians (ACCP) (14), pathological information is the key to the diagnosis. Thus, most of the present studies that focused on MPLC only enrolled patients who previously underwent surgical resection for FPLC. However, for patients that received radiotherapy for FPLC, it is much more likely to be incorrectly regarded as intrapulmonary metastasis or recurrence when they developed a SPLC, leading to missing optimal treatments. To our knowledge, very few studies have focused on the occurrence of SPLC in patients that previously received radiotherapy for FPLC. The SEER database provided the potential study population of SPLC patients, though by its own definition of multiple primaries.

The standard radical surgery for lung cancer patients remains to be lobectomy, which achieves a sufficient and safe excision region of tumor tissues, but causes more comorbidities and higher mortalities than sublevel resection 

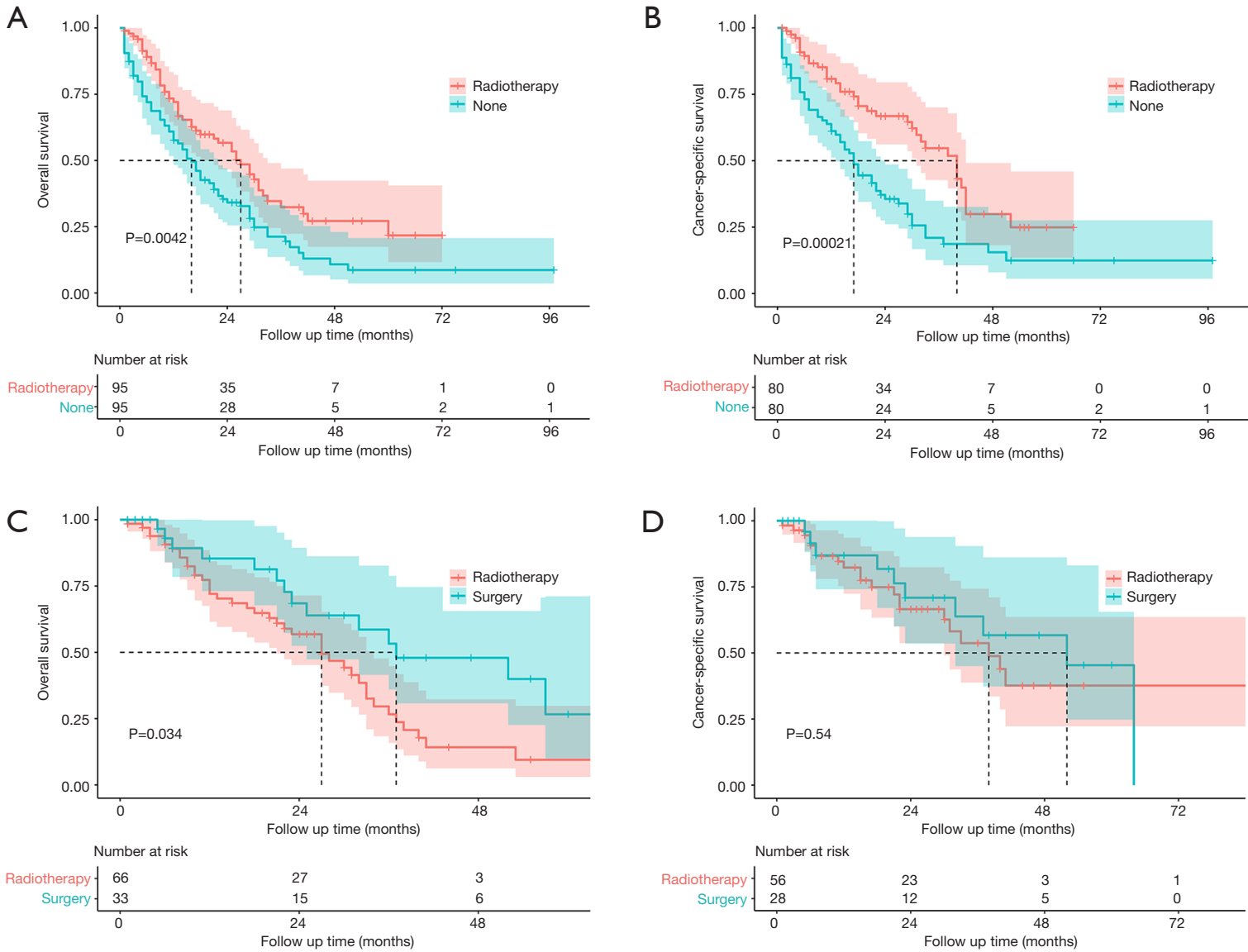

Figure 4 Survival analysis for SPLC after PSM between radiotherapy and none-treatment (A,B) or surgery (C,D) groups. SPLC, second primary lung cancer; PSM, propensity score matching.

or other noninvasive alternatives. Radiotherapy, led by SABR recently, demonstrated encouraging therapeutic effects with limited incidence of complications on earlystage lung cancer $(11,15)$. For inoperable patients with early-stage lung cancer, SABR might be the first choice and showed similar prognosis to surgical procedures $(8,9)$, though the long-term survival outcome needs to be further validated by randomized controlled trials. Actually, the previous studies indicated the feasibility of surgical resection for SPLC, and showed a great survival outcome (16-18), but whether radiotherapy is equally effective remains unclear. Considering that SPLC patients had suffered the FPLC, the physical conditions and pulmonary function reserve may not permit another surgery. Thus, SABR shows a great potential in terms of the treatment of SPLC.

This study identified the SPLC patients that previously received radiotherapy for clinical T1 stage FPLC from the SEER database. Besides age $>62$ years (HR: 1.48, 95\%
CI: $1.10-1.99 ; \mathrm{P}=0.010)$ and tumor size $>1 \mathrm{~cm}$ of SPLC (HR: $1.95,95 \%$ CI: $1.51-2.53 ; \mathrm{P}<0.001$ ), we found that the survival time was also significantly associated with therapy strategies (Table 1). It seemed that performing surgery or radiotherapy could significantly improve survival (Figure $2 C, D ; \mathrm{P}<0.05$ ). However, patients that received chemotherapy had a worse survival than those who did not. This might attribute to the fact that chemotherapy was usually considered for seriously-ill diseases, such as lymph node metastasis or distant metastasis. Additionally, radiotherapy showed a slightly worse survival outcome than surgery, though difference was not significant. Nevertheless, both of radiotherapy and surgery groups performed with significantly better OS and CSS than none-treatment group and other therapy groups before PSM.

PSM is an effective method to minimize the side effects of confounding factors. The survival comparisons between radiotherapy and other groups were performed with well- 
A

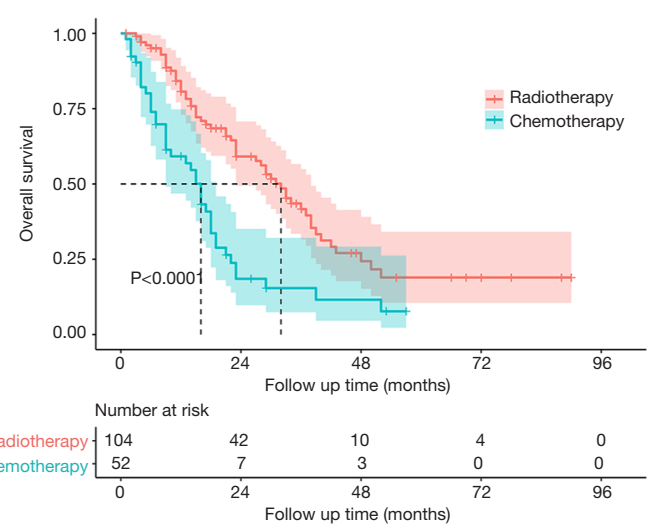

C

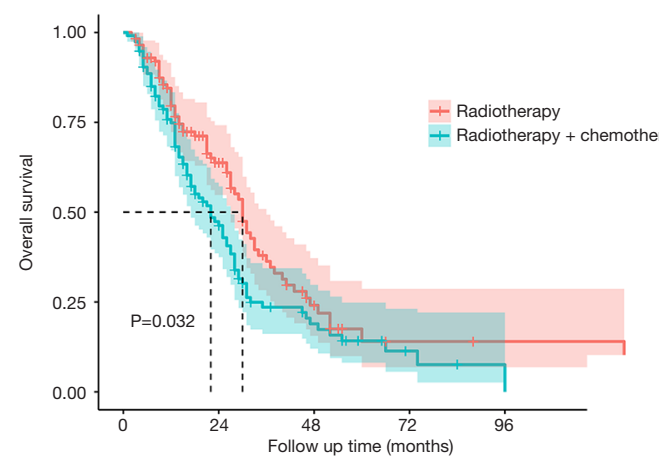

B

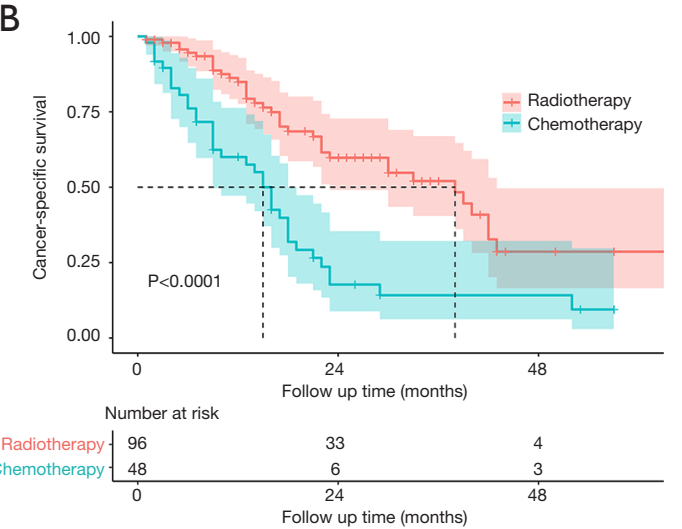

D

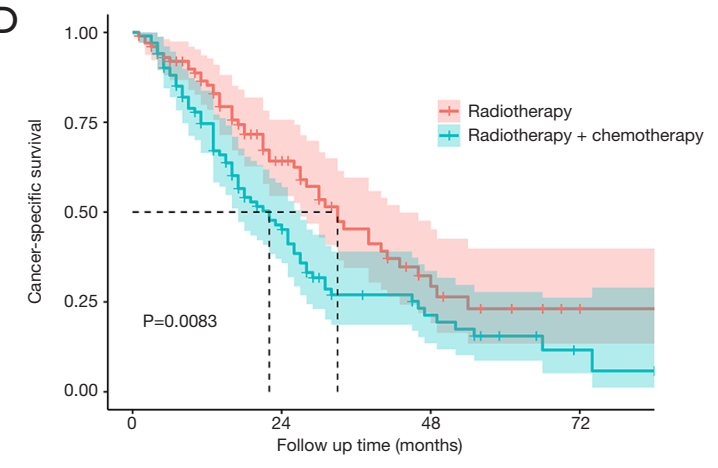

Number at risk

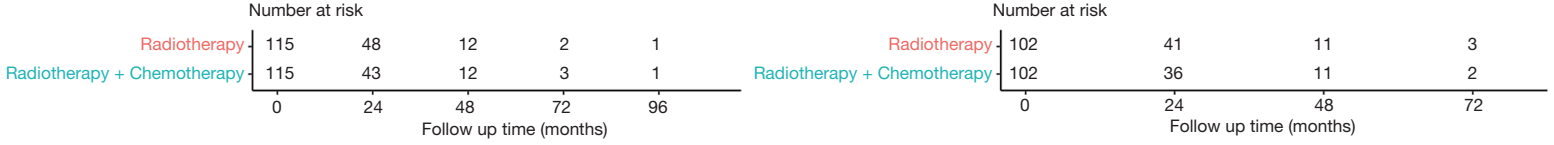

Figure 5 Survival analysis for SPLC after PSM between radiotherapy and chemotherapy (A,B) or radiotherapy plus chemotherapy (C,D) groups. SPLC, second primary lung cancer; PSM, propensity score matching.

matched baseline data (Tables S1-S4). Similar to the differences before matching, the radiotherapy group demonstrated significantly better OS and CSS than none-treatment, chemotherapy and radiotherapy plus chemotherapy groups after $\mathrm{PSM}(\mathrm{P}<0.05 ;$ Figures 4,5$)$. However, the surgery group had a significantly better OS than radiotherapy $(\mathrm{P}=0.034$; Figure $4 C)$, but no such significance was observed in the CSS curve $(\mathrm{P}=0.540$; Figure $4 D)$. Although there was a limited number of patients that underwent surgery and the CSS was not significantly different between surgery and radiotherapy groups, surgical resection might be more beneficial to the survival for SPLC patients. Thus, surgical procedures should be considered first if other conditions permitted. Despite that, many SPLC patients might not tolerate the surgery because of having suffered the treatments on FPLC. Then SABR might be an effective alternative, which had been accepted for SPLC in previous studies $(19,20)$.

In addition to the clinical implications, there were several methodological innovations in our study. Firstly, considering the difficulty in establishing a large study cohort of SPLC, the SEER database provides a lot of data of MPLC patients for researches. Secondly, to identify potential prognostic factors for SPLC, a k-adaptive partitioning algorithm was used for the optimal categorization of continuous variables, which is based on survival data and minimizes information loss (13). Thirdly, the application of PSM made the survival comparisons more reliable between treatment groups.

There are also some limitations that should be noted in this study. The analyses we performed were based on the observational and retrospective data from the SEER database. Thus, the data bias and heterogeneity of the population could not be avoided. In addition, the definition criteria of MPLC in this database was not totally consistent 
with Martini's (3) or ACCP's (14), which mainly relies on pathological information. This was limited by the study population itself because the pathological data was unavailable for patients that received radiotherapy for FPLC. Furthermore, the surgery group consisted of much fewer patients than the radiotherapy group. This might attribute to the fact that many patients could not tolerate the surgery, otherwise they could have received surgery for FPLC. Therefore, whether surgical resection is more beneficial to survival than radiotherapy deserves further investigation in the future.

\section{Conclusions}

For patients who underwent radiotherapy for FPLC, the survival outcome following the treatment of SPLC was significantly associated with age $>62$ years, SPLC tumor size $>1 \mathrm{~cm}$ and treatment strategies for SPLC including surgery, radiotherapy and chemotherapy. Overall, surgical resection may be more beneficial to survival than other treatments and should be considered first when patients' physical conditions permit. However, if patients cannot tolerate surgery, radiotherapy can be an effective alternative.

\section{Acknowledgments}

Funding: This study was supported by a grant from the Ministry of Science and Technology of the People's Republic of China (Grant Number 2016YFC0105207).

\section{Footnote}

Reporting Checklist: The authors have completed the STROBE reporting checklist. Available at http://dx.doi. org/10.21037/jtd-20-2024

Conflicts of Interest: All authors have completed the ICMJE uniform disclosure form (available at http://dx.doi. org/10.21037/jtd-20-2024). The authors have no conflicts of interest to declare.

Ethical Statement: The authors are accountable for all aspects of the work in ensuring that questions related to the accuracy or integrity of any part of the work are appropriately investigated and resolved. The study was conducted in accordance with the Declaration of Helsinki (as revised in 2013). The SEER database was used publicly, all data included are anonymous and the relevant requirement about informed consent was thus waived. This study has been approved to be exempted research for no human subject involved by the Ethics Committee of Peking Union Medical College Hospital.

Open Access Statement: This is an Open Access article distributed in accordance with the Creative Commons Attribution-NonCommercial-NoDerivs 4.0 International License (CC BY-NC-ND 4.0), which permits the noncommercial replication and distribution of the article with the strict proviso that no changes or edits are made and the original work is properly cited (including links to both the formal publication through the relevant DOI and the license). See: https://creativecommons.org/licenses/by-nc-nd/4.0/.

\section{References}

1. Siegel RL, Miller KD, Jemal A. Cancer statistics, 2019. CA Cancer J Clin 2019;69:7-34.

2. de Koning HJ, van der Aalst CM, de Jong PA, et al. Reduced lung-cancer mortality with volume CT screening in a randomized trial. N Engl J Med 2020;382:503-13.

3. Martini N, Melamed MR. Multiple primary lung cancers. J Thorac Cardiovasc Surg 1975;70:606-12.

4. Wu B, Cui Y, Tian J, et al. Effect of second primary cancer on the prognosis of patients with non-small cell lung cancer. J Thorac Dis 2019;11:573-82.

5. Thakur MK, Ruterbusch JJ, Schwartz AG, et al. Risk of second lung cancer in patients with previously treated lung cancer: analysis of Surveillance, Epidemiology, and End Results (SEER) Data. J Thorac Oncol 2018;13:46-53.

6. Lancia A, Merizzoli E, Filippi AR. The 8th UICC/AJCC TNM edition for non-small cell lung cancer staging: getting off to a flying start? Ann Transl Med 2019;7:S205.

7. Frick MA, Feigenberg SJ, Jean-Baptiste SR, et al. Circulating tumor cells are associated with recurrent disease in patients with early-stage non-small cell lung cancer treated with stereotactic body radiotherapy. Clin Cancer Res 2020;26:2372-80.

8. Shirvani SM, Jiang J, Chang JY, et al. Lobectomy, sublobar resection, and stereotactic ablative radiotherapy for earlystage non-small cell lung cancers in the elderly. JAMA Surg 2014;149:1244-53.

9. Scotti V, Bruni A, Francolini G, et al. Stereotactic ablative radiotherapy as an alternative to lobectomy in patients with medically operable stage I NSCLC: a retrospective, multicenter analysis. Clin Lung Cancer 2019;20:e53-61.

10. Adamo M, Dickie L, Ruhl J. SEER Program Coding and 
Staging Manual 2018. Bethesda: National Cancer Institute, 2018:20892.

11. Grills IS, Mangona VS, Welsh R, et al. Outcomes after stereotactic lung radiotherapy or wedge resection for stage I non-small-cell lung cancer. J Clin Oncol 2010;28:928-35.

12. Goldstraw P, Chansky K, Crowley J, et al. The IASLC lung cancer staging project: proposals for revision of the TNM stage groupings in the forthcoming (eighth) edition of the TNM classification for lung cancer. J Thorac Oncol 2016;11:39-51.

13. Eo SH, Kang HY, Hong SM, et al. K-adaptive partitioning for survival data, with an application to cancer staging. 2014. arXiv:1306.4615.

14. Shen KR, Meyers BF, Larner JM, et al. Special treatment issues in lung cancer: ACCP evidencebased clinical practice guidelines (2nd edition). Chest 2007;132:290S-305S.

15. Chi A, Liao Z, Nguyen NP, et al. Systemic review of the patterns of failure following stereotactic body radiation therapy in early-stage non-small-cell lung cancer: clinical

Cite this article as: Wu Y, Han C, Zhu J, Chong Y, Liu J, Gong L, Liu Z, Hu K, Zhang F. Prognostic outcome after second primary lung cancer in patients with previously treated lung cancer by radiotherapy. J Thorac Dis 2020;12(10):5376-5386. doi: 10.21037/jtd-20-2024 implications. Radiother Oncol 2010;94:1-11.

16. Hamaji M, Allen MS, Cassivi SD, et al. Surgical treatment of metachronous second primary lung cancer after complete resection of non-small cell lung cancer. J Thorac Cardiovasc Surg 2013;145:683-90; discussion 690-1.

17. Yang J, Liu M, Fan J, et al. Surgical treatment of metachronous second primary lung cancer. Ann Thorac Surg 2014;98:1192-8.

18. Muranishi Y, Sonobe M, Hamaji M, et al. Surgery for metachronous second primary lung cancer versus surgery for primary lung cancer: a propensity score-matched comparison of postoperative complications and survival outcomes. Interact Cardiovasc Thorac Surg 2018;26:631-7.

19. Nikitas J, DeWees T, Rehman S, et al. Stereotactic body radiotherapy for early-stage multiple primary lung cancers. Clin Lung Cancer 2019;20:107-16.

20. Creach KM, Bradley JD, Mahasittiwat P, et al. Stereotactic body radiation therapy in the treatment of multiple primary lung cancers. Radiother Oncol 2012;104:19-22. 
A

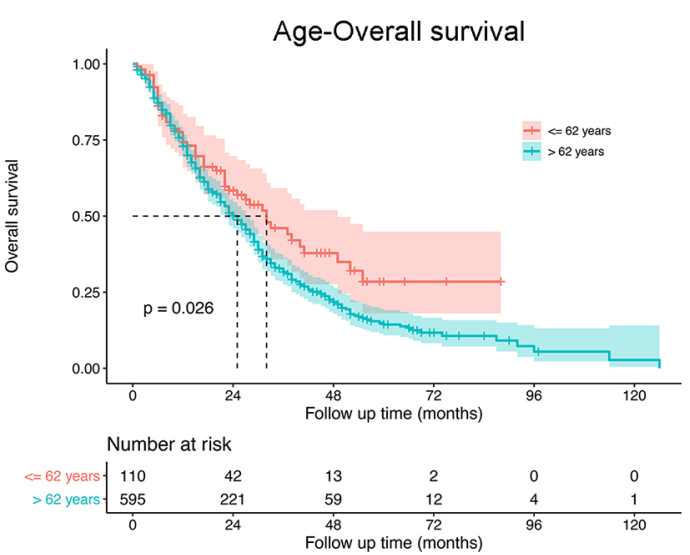

C
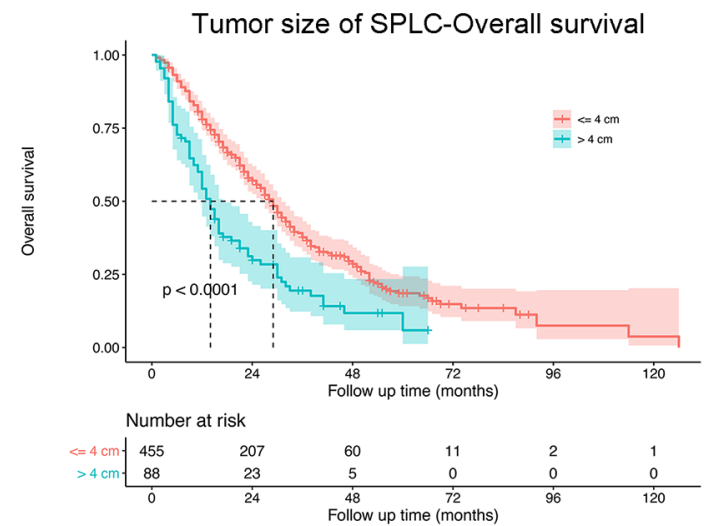

B

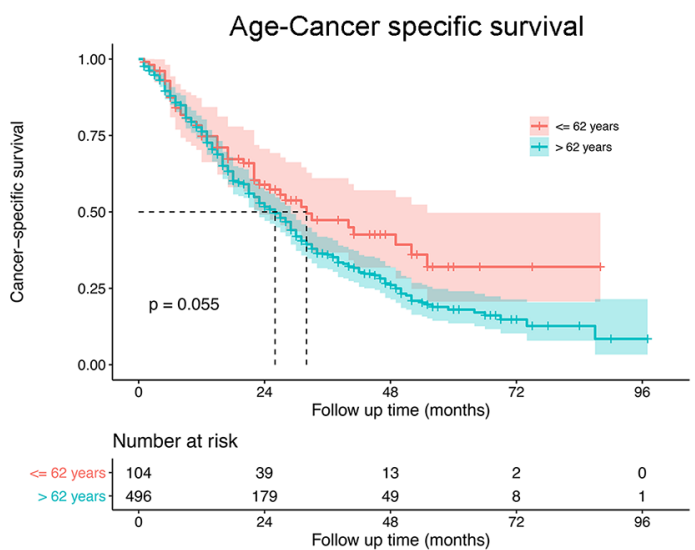

D

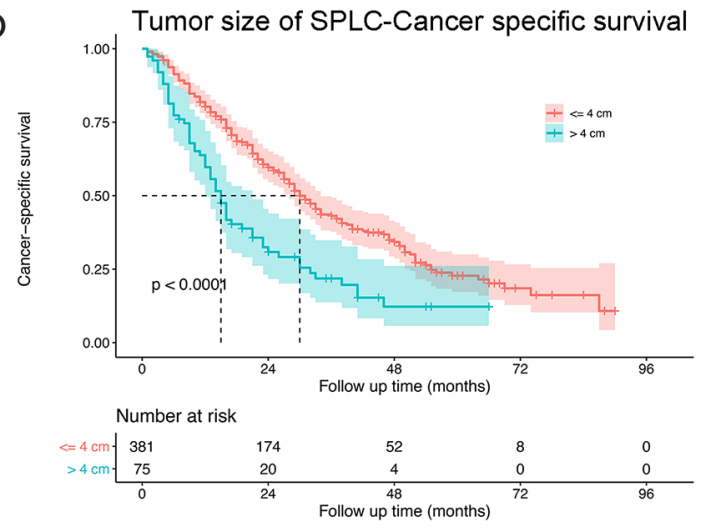

Figure S1 The OS and lung CSS between the groups according to age and SPLC tumor size. OS, overall survival; CSS, cancer-specific survival. 
A
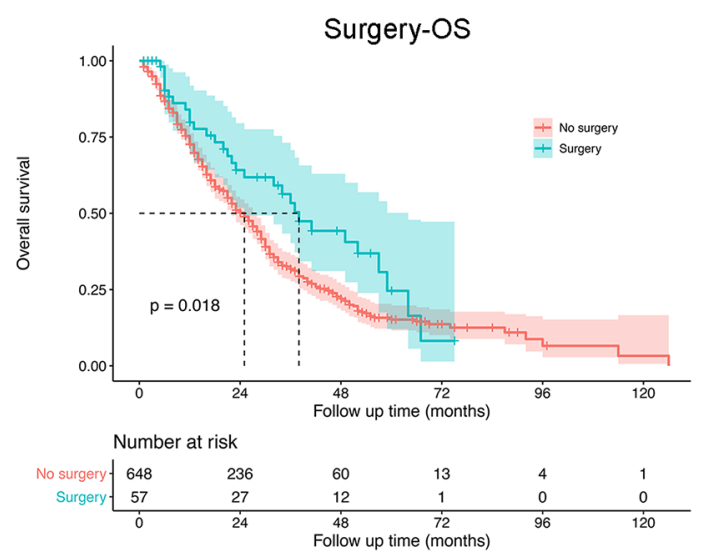

C
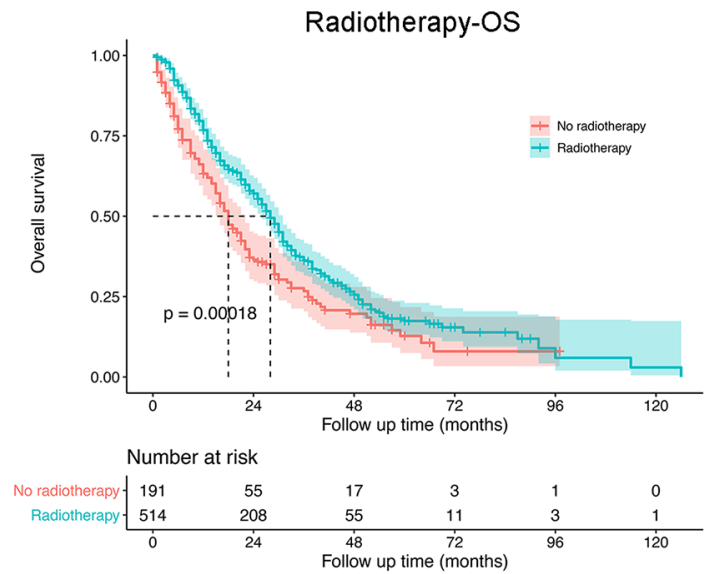

$\mathrm{E}$

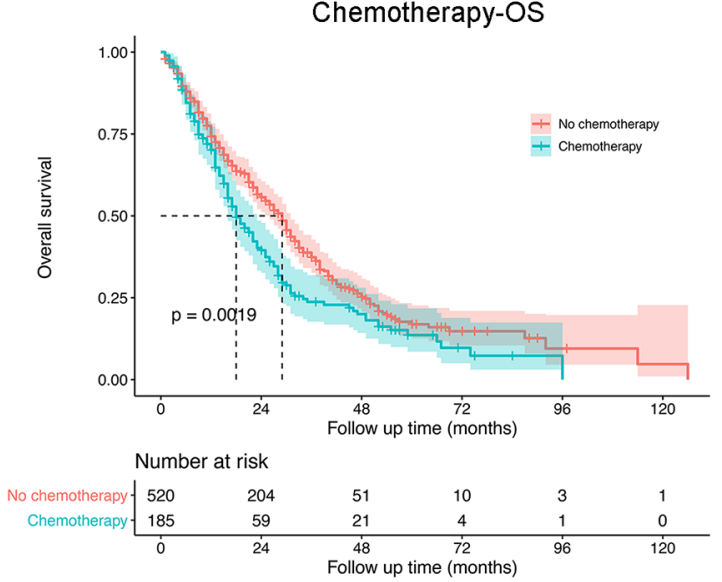

B
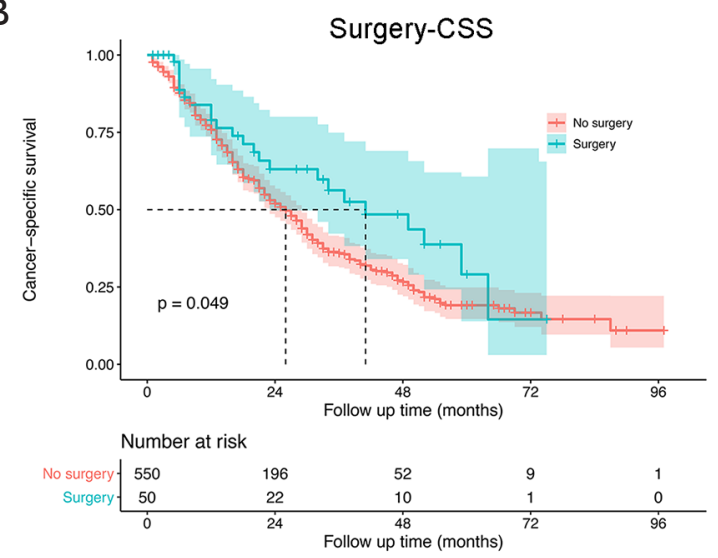

D Radiotherapy-CSS
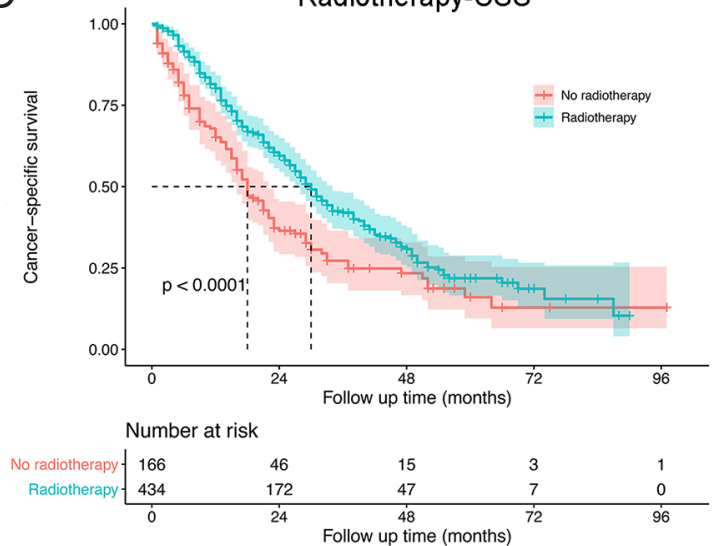

$\mathrm{F}$
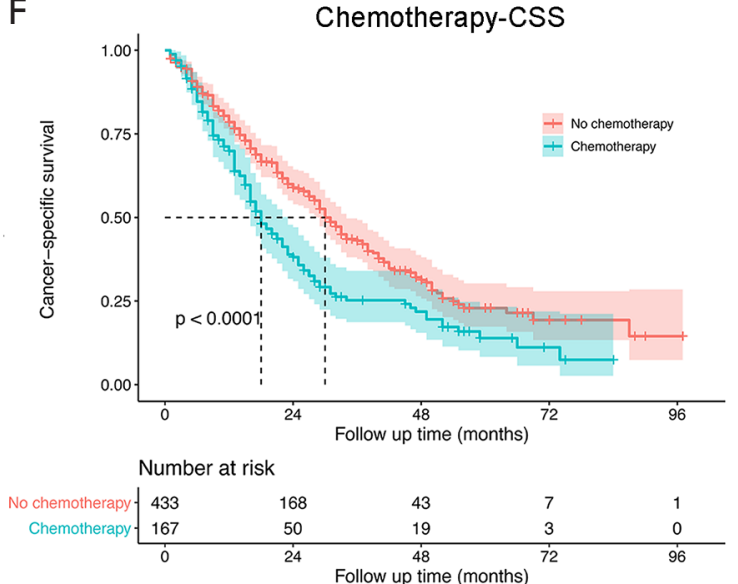

Figure S2 The OS and lung CSS between surgery and no surgery, between radiotherapy and no radiotherapy, and between chemotherapy and no chemotherapy. OS, overall survival; CSS, cancer-specific survival. 
Table S1 Baseline characteristics after PSM between radiotherapy and none-treatment groups

\begin{tabular}{|c|c|c|c|c|c|c|}
\hline \multirow{2}{*}{ Characteristics } & \multicolumn{3}{|c|}{ Match for OS } & \multicolumn{3}{|c|}{ Match for lung CSS } \\
\hline & Radiotherapy & None & $P$ value & Radiotherapy & None & $P$ value \\
\hline All & 95 & 95 & & 80 & 80 & \\
\hline Age $>62$ years & $81(85.3)$ & $81(85.3)$ & 1.000 & $66(82.5)$ & $66(82.5)$ & 1.000 \\
\hline Race & & & 0.174 & & & 0.411 \\
\hline White & $86(90.5)$ & $77(81.1)$ & & $71(88.8)$ & 65 (81.2) & \\
\hline Black & $7(7.4)$ & $14(14.7)$ & & $7(8.8)$ & $12(15.0)$ & \\
\hline Others & $2(2.1)$ & $4(4.2)$ & & $2(2.5)$ & $3(3.8)$ & \\
\hline Female & $50(52.6)$ & $51(53.7)$ & 1.000 & $55(68.8)$ & $42(52.5)$ & 0.052 \\
\hline \multicolumn{7}{|l|}{ FPLC } \\
\hline Tumor size $>1 \mathrm{~cm}$ & 87 (91.6) & $88(92.6)$ & 1.000 & 77 (96.2) & $73(91.2)$ & 0.327 \\
\hline Laterality-left & $53(55.8)$ & $45(47.4)$ & 0.310 & $36(45.0)$ & $36(45.0)$ & 1.000 \\
\hline $\mathrm{N}$ stage (N1/2/3) & $15(15.8)$ & $28(29.5)$ & 0.037 & $13(16.2)$ & $24(30.0)$ & 0.061 \\
\hline M stage (M1) & $9(9.5)$ & $12(12.6)$ & 0.644 & $11(13.8)$ & $10(12.5)$ & 1.000 \\
\hline Tumor site & & & 0.699 & & & 0.560 \\
\hline Upper lobe & $60(63.2)$ & $59(62.1)$ & & $54(67.5)$ & $52(65.0)$ & \\
\hline Middle lobe & $4(4.2)$ & $6(6.3)$ & & $3(3.8)$ & $6(7.5)$ & \\
\hline Lower lobe & $28(29.5)$ & $29(30.5)$ & & $20(25.0)$ & $21(26.2)$ & \\
\hline Unknown & $3(3.2)$ & $1(1.1)$ & & $3(3.8)$ & $1(1.2)$ & \\
\hline Chemotherapy & $11(11.6)$ & $28(29.5)$ & 0.004 & $8(10.0)$ & 27 (33.8) & 0.001 \\
\hline \multicolumn{7}{|l|}{ SPLC } \\
\hline Tumor size, $\mathrm{cm}$ & & & 1.000 & & & 1.000 \\
\hline$\leq 4.0$ & $45(47.4)$ & $45(47.4)$ & & $39(48.8)$ & $39(48.8)$ & \\
\hline$>4.0$ & $15(15.8)$ & 15 (15.8) & & $11(13.8)$ & $11(13.8)$ & \\
\hline Unknown & $35(36.8)$ & $35(36.8)$ & & $30(37.5)$ & $30(37.5)$ & \\
\hline Laterality & & & 0.063 & & & 0.064 \\
\hline Right & $56(58.9)$ & 49 (51.6) & & $40(50.0)$ & 41 (51.2) & \\
\hline Left & $39(41.1)$ & 41 (43.2) & & $40(50.0)$ & $34(42.5)$ & \\
\hline Unknown & $0(0.0)$ & $5(5.3)$ & & $0(0.0)$ & $5(6.2)$ & \\
\hline Tumor site & & & 0.004 & & & 0.017 \\
\hline Upper lobe & $0(0.0)$ & $6(6.3)$ & & $1(1.2)$ & $4(5.0)$ & \\
\hline Middle lobe & $51(53.7)$ & $47(49.5)$ & & 45 (56.2) & $42(52.5)$ & \\
\hline Lower lobe & $6(6.3)$ & $4(4.2)$ & & $5(6.2)$ & $4(5.0)$ & \\
\hline Main bronchus & $36(37.9)$ & $26(27.4)$ & & $28(35.0)$ & $19(23.8)$ & \\
\hline Unknown & $2(2.1)$ & $12(12.6)$ & & $1(1.2)$ & $11(13.8)$ & \\
\hline Surgery & 0 & 0 & - & 0 & 0 & - \\
\hline Radiotherapy & 95 & 0 & - & 80 & 0 & - \\
\hline Chemotherapy & 0 & 0 & - & 0 & 0 & - \\
\hline
\end{tabular}

PSM, propensity score matching; OS, overall survival; CSS, cancer-specific survival; FPLC, first primary lung cancer; SPLC, second primary lung cancer. 
Table S2 Baseline characteristics after PSM between radiotherapy and surgery groups

\begin{tabular}{|c|c|c|c|c|c|c|}
\hline \multirow{2}{*}{ Characteristics } & \multicolumn{3}{|c|}{ Match for OS } & \multicolumn{3}{|c|}{ Match for lung CSS } \\
\hline & Radiotherapy & Surgery & $P$ value & Radiotherapy & Surgery & $P$ value \\
\hline All & 66 & 33 & & 56 & 28 & \\
\hline Age $>62$ years & $36(54.5)$ & $18(54.5)$ & 1.000 & $26(46.4)$ & $13(46.4)$ & 1.000 \\
\hline Race & & & 0.186 & & & 0.411 \\
\hline White & $57(86.4)$ & $27(81.8)$ & & $48(85.7)$ & $23(82.1)$ & \\
\hline Black & $8(12.1)$ & $3(9.1)$ & & $6(10.7)$ & $3(10.7)$ & \\
\hline Others & $1(1.5)$ & $3(9.1)$ & & $2(3.6)$ & $2(7.1)$ & \\
\hline Female & & & & 33 (58.9) & $16(57.1)$ & 0.052 \\
\hline \multicolumn{7}{|l|}{ FPLC } \\
\hline Tumor size $>1 \mathrm{~cm}$ & $64(97.0)$ & $33(100.0)$ & 0.801 & $53(94.6)$ & $28(100.0)$ & 0.533 \\
\hline Laterality-left & $34(51.5)$ & $11(33.3)$ & 0.134 & $25(44.6)$ & $8(28.6)$ & 0.236 \\
\hline $\mathrm{N}$ stage (N1/2/3) & $9(13.6)$ & $14(42.4)$ & 0.003 & $11(19.6)$ & $13(46.4)$ & 0.021 \\
\hline M stage (M1) & 9 (13.6) & $4(12.1)$ & 1.000 & $8(14.3)$ & $4(14.3)$ & 1.000 \\
\hline Tumor site & & & 0.591 & & & 0.566 \\
\hline Upper lobe & $1(1.5)$ & $1(3.0)$ & & $0(0.0)$ & $1(3.6)$ & \\
\hline Middle lobe & $31(47.0)$ & $19(57.6)$ & & 33 (58.9) & $16(57.1)$ & \\
\hline Lower lobe & $5(7.6)$ & $3(9.1)$ & & $6(10.7)$ & $3(10.7)$ & \\
\hline Main bronchus & $26(39.4)$ & $10(30.3)$ & & $17(30.4)$ & 8 (28.6) & \\
\hline Unknown & $3(4.5)$ & $0(0.0)$ & & $0(0.0)$ & $0(0.0)$ & \\
\hline Chemotherapy & 7 (10.6) & $17(51.5)$ & $<0.001$ & $6(10.7)$ & $16(57.1)$ & $<0.001$ \\
\hline \multicolumn{7}{|l|}{ SPLC } \\
\hline Tumor size, $\mathrm{cm}$ & & & 0.966 & & & 0.965 \\
\hline$\leq 4.0$ & $45(68.2)$ & $22(66.7)$ & & 35 (62.5) & $17(60.7)$ & \\
\hline$>4.0$ & $5(7.6)$ & $3(9.1)$ & & $5(8.9)$ & $3(10.7)$ & \\
\hline Unknown & $16(24.2)$ & $8(24.2)$ & & $16(28.6)$ & 8 (28.6) & \\
\hline Laterality-left & 34 (51.5) & $14(42.4)$ & 0.063 & $29(51.8)$ & $13(46.4)$ & 0.817 \\
\hline Tumor site & & & 0.800 & & & 0.922 \\
\hline Upper lobe & $1(1.5)$ & $0(0.0)$ & & $34(60.7)$ & $16(57.1)$ & \\
\hline Middle lobe & $42(63.6)$ & $18(54.5)$ & & $3(5.4)$ & $1(3.6)$ & \\
\hline Lower lobe & $4(6.1)$ & $2(6.1)$ & & $18(32.1)$ & $10(35.7)$ & \\
\hline Main bronchus & $18(27.3)$ & $12(36.4)$ & & $0(0.0)$ & $0(0.0)$ & \\
\hline Unknown & $1(1.5)$ & $1(3.0)$ & & $1(1.8)$ & $1(3.6)$ & \\
\hline Surgery & 0 & 33 & - & 0 & 28 & - \\
\hline Radiotherapy & 66 & 0 & - & 56 & 0 & - \\
\hline Chemotherapy & 0 & 0 & - & 0 & 0 & - \\
\hline
\end{tabular}

PSM, propensity score matching; OS, overall survival; CSS, cancer-specific survival; FPLC, first primary lung cancer; SPLC, second primary lung cancer. 
Table S3 Baseline characteristics after PSM between radiotherapy and chemotherapy groups

\begin{tabular}{|c|c|c|c|c|c|c|}
\hline \multirow{2}{*}{ Characteristics } & \multicolumn{3}{|c|}{ Match for OS } & \multicolumn{3}{|c|}{ Match for lung CSS } \\
\hline & Radiotherapy & Chemotherapy & $P$ value & Radiotherapy & Chemotherapy & $P$ value \\
\hline All & 104 & 52 & & 96 & 48 & \\
\hline Age $>62$ years & $82(78.8)$ & $41(78.8)$ & 1.000 & $76(79.2)$ & 38 (79.2) & 1.000 \\
\hline Race & & & 0.928 & & & 0.783 \\
\hline White & $92(88.5)$ & $45(86.5)$ & & $78(81.2)$ & $41(85.4)$ & \\
\hline Black & $9(8.7)$ & $5(9.6)$ & & $14(14.6)$ & $5(10.4)$ & \\
\hline Others & $3(2.9)$ & $2(3.8)$ & & $4(4.2)$ & $2(4.2)$ & \\
\hline Female & $59(56.7)$ & 32 (61.5) & 0.688 & $58(60.4)$ & $29(60.4)$ & 1.000 \\
\hline \multicolumn{7}{|l|}{ FPLC } \\
\hline Tumor size $>1 \mathrm{~cm}$ & $95(91.3)$ & $51(98.1)$ & 0.204 & $92(95.8)$ & 47 (97.9) & 0.872 \\
\hline Laterality-left & $53(51.0)$ & $24(46.2)$ & 0.692 & $51(53.1)$ & $22(45.8)$ & 0.517 \\
\hline $\mathrm{N}$ stage $(\mathrm{N} 1 / 2 / 3)$ & $16(15.4)$ & $28(53.8)$ & $<0.001$ & $19(19.8)$ & $25(52.1)$ & $<0.001$ \\
\hline M stage (M1) & $13(12.5)$ & $6(11.5)$ & 1.000 & $11(11.5)$ & $6(12.5)$ & 1.000 \\
\hline Tumor site & & & 0.174 & & & 0.726 \\
\hline Upper lobe & $1(1.0)$ & $0(0.0)$ & & $70(72.9)$ & $35(72.9)$ & \\
\hline Middle lobe & $73(70.2)$ & $37(71.2)$ & & $3(3.1)$ & $3(6.2)$ & \\
\hline Lower lobe & $2(1.9)$ & $3(5.8)$ & & $22(22.9)$ & $10(20.8)$ & \\
\hline Main bronchus & 20 (19.2) & $12(23.1)$ & & $0(0.0)$ & $0(0.0)$ & \\
\hline Unknown & $8(7.7)$ & $0(0.0)$ & & $1(1.0)$ & $0(0.0)$ & \\
\hline Chemotherapy & $14(13.5)$ & $31(59.6)$ & $<0.001$ & $15(15.6)$ & $27(56.2)$ & $<0.001$ \\
\hline \multicolumn{7}{|l|}{ SPLC } \\
\hline Tumor size, $\mathrm{cm}$ & & & 1.000 & & & 1.000 \\
\hline$\leq 4.0$ & $60(57.7)$ & $30(57.7)$ & & $56(58.3)$ & $28(58.3)$ & \\
\hline$>4.0$ & $10(9.6)$ & $5(9.6)$ & & $10(10.4)$ & $5(10.4)$ & \\
\hline Unknown & $34(32.7)$ & $17(32.7)$ & & $30(31.2)$ & $15(31.2)$ & \\
\hline Laterality & & & 0.238 & & & 0.203 \\
\hline Right & 55 (52.9) & $31(59.6)$ & & $50(52.1)$ & $29(60.4)$ & \\
\hline Left & $49(47.1)$ & $20(38.5)$ & & $46(47.9)$ & $18(37.5)$ & \\
\hline Unknown & $0(0.0)$ & $1(1.9)$ & & $0(0.0)$ & $1(2.1)$ & \\
\hline Tumor site & & & 0.446 & & & 0.229 \\
\hline Upper lobe & $55(52.9)$ & 27 (51.9) & & $1(1.0)$ & $0(0.0)$ & \\
\hline Middle lobe & $4(3.8)$ & $4(7.7)$ & & $58(60.4)$ & $23(47.9)$ & \\
\hline Lower lobe & 41 (39.4) & $17(32.7)$ & & $6(6.2)$ & $4(8.3)$ & \\
\hline Main bronchus & $0(0.0)$ & $1(1.9)$ & & $30(31.2)$ & $17(35.4)$ & \\
\hline Unknown & $4(3.8)$ & $3(5.8)$ & & $1(1.0)$ & $4(8.3)$ & \\
\hline Surgery & 0 & 0 & - & 0 & 0 & - \\
\hline Radiotherapy & 104 & 0 & - & 96 & 0 & - \\
\hline Chemotherapy & 0 & 52 & - & 0 & 48 & - \\
\hline
\end{tabular}

PSM, propensity score matching; OS, overall survival; CSS, cancer-specific survival; FPLC, first primary lung cancer; SPLC, second primary lung cancer. 
Table S4 Baseline characteristics after PSM between radiotherapy and radiotherapy plus chemotherapy groups

\begin{tabular}{|c|c|c|c|c|c|c|}
\hline \multirow[b]{2}{*}{ Characteristic } & \multicolumn{3}{|c|}{ Match for OS } & \multicolumn{3}{|c|}{ Match for lung CSS } \\
\hline & Radiotherapy & $\begin{array}{l}\text { Radiotherapy + } \\
\text { chemotherapy }\end{array}$ & $P$ value & Radiotherapy & $\begin{array}{l}\text { Radiotherapy + } \\
\text { chemotherapy }\end{array}$ & $P$ value \\
\hline All & 115 & 115 & & 102 & 102 & \\
\hline Age $>62$ years & $91(79.1)$ & $91(79.1)$ & 1.000 & 79 (77.5) & 79 (77.5) & 1.000 \\
\hline Race & & & 0.564 & & & 0.769 \\
\hline White & $96(83.5)$ & $95(82.6)$ & & $85(83.3)$ & $83(81.4)$ & \\
\hline Black & $14(12.2)$ & $13(11.3)$ & & $13(12.7)$ & $13(12.7)$ & \\
\hline Others & $5(4.3)$ & $5(4.3)$ & & $4(3.9)$ & $5(4.9)$ & \\
\hline Unknown & $0(0.0)$ & $2(1.7)$ & & $0(0.0)$ & $1(1.0)$ & \\
\hline Female & $58(50.4)$ & $64(55.7)$ & 0.509 & $54(52.9)$ & $59(57.8)$ & 0.57 \\
\hline \multicolumn{7}{|l|}{ FPLC } \\
\hline Tumor size $>1 \mathrm{~cm}$ & $105(91.3)$ & $107(93.0)$ & 0.806 & 93 (91.2) & 94 (92.2) & 1.000 \\
\hline Laterality-left & $66(57.4)$ & $54(47.0)$ & 0.146 & $54(52.9)$ & $50(49.0)$ & 0.674 \\
\hline $\mathrm{N}$ stage (N1/2/3) & $18(15.7)$ & $42(36.5)$ & 0.001 & $16(15.7)$ & $38(37.3)$ & 0.001 \\
\hline M stage (M1) & $8(7.0)$ & $20(17.4)$ & 0.027 & $14(13.7)$ & $18(17.6)$ & 0.564 \\
\hline Tumor site & & & 0.942 & & & 0.785 \\
\hline Upper lobe & $1(0.9)$ & $1(0.9)$ & & $0(0.0)$ & $1(1.0)$ & \\
\hline Middle lobe & $70(60.9)$ & 75 (65.2) & & 73 (71.6) & $67(65.7)$ & \\
\hline Lower lobe & $6(5.2)$ & $4(3.5)$ & & $3(2.9)$ & $3(2.9)$ & \\
\hline Main bronchus & $34(29.6)$ & $32(27.8)$ & & $24(23.5)$ & $29(28.4)$ & \\
\hline Unknown & $4(3.5)$ & $3(2.6)$ & & $2(2.0)$ & $2(2.0)$ & \\
\hline Chemotherapy & 14 (12.2) & $81(70.4)$ & $<0.001$ & $12(11.8)$ & $69(67.6)$ & $<0.001$ \\
\hline \multicolumn{7}{|l|}{ SPLC } \\
\hline Tumor size, cm & & & 0.938 & & & 0.983 \\
\hline$\leq 4.0$ & $71(61.7)$ & $69(60.0)$ & & $62(60.8)$ & $61(59.8)$ & \\
\hline$>4.0$ & $19(16.5)$ & $21(18.3)$ & & $19(18.6)$ & $20(19.6)$ & \\
\hline Unknown & $25(21.7)$ & $25(21.7)$ & & $21(20.6)$ & 21 (20.6) & \\
\hline \multicolumn{7}{|l|}{ Laterality } \\
\hline Right & $65(56.5)$ & $61(53.0)$ & 0.127 & $61(59.8)$ & $56(54.9)$ & 0.314 \\
\hline Left & $50(43.5)$ & $50(43.5)$ & & $41(40.2)$ & $44(43.1)$ & \\
\hline Unknown & $0(0.0)$ & $4(3.5)$ & & $0(0.0)$ & $2(2.0)$ & \\
\hline Tumor site & & & 0.020 & & & 0.281 \\
\hline Upper lobe & $0(0.0)$ & $3(2.6)$ & & $1(1.0)$ & $3(2.9)$ & \\
\hline Middle lobe & $79(68.7)$ & $59(51.3)$ & & $56(54.9)$ & $52(51.0)$ & \\
\hline Lower lobe & $6(5.2)$ & $3(2.6)$ & & $5(4.9)$ & $3(2.9)$ & \\
\hline Main bronchus & 27 (23.5) & $40(34.8)$ & & 39 (38.2) & 37 (36.3) & \\
\hline Unknown & $3(2.6)$ & $10(8.7)$ & & $1(1.0)$ & $7(6.9)$ & \\
\hline Surgery & 0 & 0 & - & 0 & 0 & - \\
\hline Radiotherapy & 115 & 115 & - & 102 & 102 & - \\
\hline Chemotherapy & 0 & 115 & - & 0 & 102 & - \\
\hline
\end{tabular}

PSM, propensity score matching; OS, overall survival; CSS, cancer-specific survival; FPLC, first primary lung cancer; SPLC, second primary lung cancer. 